\title{
LEVANTAMENTO CLÍNICO E EPIDEMIOLÓGICO DE LESÕES ORAIS VERRUCOSAS, ASSOCIADAS AO HPV, DIAGNOSTICADAS NO CENTRO DE REFERÊNCIA EM LESÕES BUCAIS DA UEFS, NO PERÍODO DE 2005 A 2017
}

\section{Dhenifer Rodrigues Paixão Santos ${ }^{1}$; Maria Emilia Santos Pereira Ramos ${ }^{2}{ }^{3}$ Tarsila de Carvalho Freitas Ramos; Adriana Santos Sena ${ }^{4}$}

1. Bolsista PROBIC/UEFS, Graduando em odontologia, Universidade Estadual de Feira de Santana, e-mail: dheniferrordrigues@hotmail.com

2. Orientador, Departamento de Saúde, Universidade Estadual de Feira de Santana, e-mail: maemilia1@uol.com.br 3. Participante do Núcleo de Câncer Oral, Departamento de Saúde, Universidade Estadual de Feira de Santana, e-mail: professoratarsila@gmail.com

4. Participante do Núcleo de Câncer Oral, Departamento de saúde, Universidade Estadual de Feira de Santana, e-mail: adrianassena@yahoo.com.br

PALAVRAS-CHAVE: patologia; papiloma; prevalência.

\section{INTRODUÇÃO}

O Papiloma Vírus Humano (HPV) trata-se de um vírus epiteliotrópico, apresentando grande afinidade pelo tecido epitelial, infectando não só os sítios de maior prevalência (região anogenital), mas também a cavidade oral (PENNACHIOTTI, et al.2016). Entre os agentes infecciosos, o vírus HPV tem sido associado à etiologia de lesões malignas como o Carcinoma Epidermóide e Verrucoso além de diversas lesões bucais benignas incluindo o papiloma escamoso, a verruga vulgar, o condiloma acuminado e a hiperplasia epitelial focal. (SOARES et al. 2002; BARRETO, et al 2014).

Apesar da grande incidência e associação com várias lesões orais, as verificações clínicas a respeito da infecção pelo HPV na cavidade oral tem sido pouco investigada pelos cirurgiões dentistas, quando comparada à infecção deste vírus em outras áreas médicas, como a ginecológica, urológica e dermatológica (BARRETO, et al. 2014).

Faz-se necessário, portanto, uma maior elucidação por parte da comunidade científica, dessa forma este estudo se propõe a discutir, rastrear e posteriormente esboçar o perfil clínico e epidemiológico dos indivíduos acometido por lesões verrucosas na população de Feira de Santana e Microrregião.

\section{MATERIAL E MÉTODOS OU METODOLOGIA (ou equivalente)}

Foram verificados os prontuários dos pacientes com laudo anatomopatológicos conclusivos para lesões orais verrucosas, associadas ao HPV e Carcinoma Epidermóide (CEC) em paciente não etilista e/ou tabagista no Centro de Referência de Lesões Bucais (CRLB-UEFS) no período de 2005-2017. Foram selecionados 64 prontuários, montado o perfil epidemiológico da população acometida e avaliadas caracteríticas referentes à lesão como: aspecto da superfíce, cor, lesão fundamental, localização de predileção, suspeita clínica e o diagnóstico histológico confirmado. O trabalho foi realizado de acordo com a resolução 466/12, sendo aprovado pelo Comitê de Ética em Pesquisa em Seres Humanos (CAAE: 0015.0.059.000-08). Os resultados foram analisados estatisticamente através do Programa IBM SPSS ${ }^{\circledR}$ STATISTICS 21 for Windows. A estatística descritiva foi apresentada através das frequências relativas e absolutas. 


\section{RESULTADOS E/OU DISCUSSÃO (ou Análise e discussão dos resultados)}

Foram selecionados 64 prontuários, sendo 59 com diagnóstico histológico de lesão verrucosa e cinco com diagnóstico de $\mathrm{CEC}$ em pacientes que não eram nem etilistas, nem tabagistas, o que pode representar uma associação com infecção pelo vírus. A infecção pelo HPV16 tem sido reconhecida como fator de risco individual para o desenvolvimento de carcinomas epidermóides, sendo relacionada ao desenvolvimento de lesões em pacientes que não apresentam os fatores clássicos de risco, como o tabagismo e o etilismo. (SILVA et al, 2011). A partir das outras 59 fichas clínicas, e como se pode observar na Tabela 1, identificou-se como a lesão verrucosa mais prevalente o papiloma escamoso $(88,1 \%)$.

Tabela 1: Distribuição das lesões orais verrucosas, em um centro de referência, Feira de Santana, 20052017

\begin{tabular}{lcc}
\hline & Frequência & $(\%)$ \\
\hline Carcinoma verrucoso & 2 & 3,4 \\
Condiloma acuminado & 1 & 1,7 \\
Papiloma escamoso & 52 & 88,1 \\
Verruga vulgar & 3 & 5,1 \\
Xantoma verruciforme & 1 & 1,7 \\
\hline Total & 59 & $100,0 \%$ \\
\hline
\end{tabular}

Fonte: Prontuários e fichas de biópsia dos pacientes atendidos no CRLB no período de 2005-2017.

Tais achados são respaldados pela literatura, no sentido que, o papiloma escamoso de fato é a lesão papilar mais comum da mucosa bucal, incluindo a parte do vermelhão do lábio, constituindo aproximadamente 3,0\% das lesões de boca (BARRETO et al, 2014). Clinicamente essas lesões eram, predominantemente, de aspecto rugoso em sua superfície $(73,0 \%)$ e coloração rósea $(56,0 \%)$. A lesão fundamental mais frequente foi a pápula $(46,8 \%)$. Essas são características típicas das lesões verrucosas: Elas podem estar localizadas em qualquer superfície mucosa. Os locais mais frequentes são a mucosa labial, a língua, a mucosa jugal e a gengiva. As lesões podem apresentar grupamentos de projeções semelhantes a espículas brancas, crescimentos rugosos roseos semelhantes a couve-flor ou pápulas sésseis ligeiramente elevadas. (NEVILLE et al, 2016).

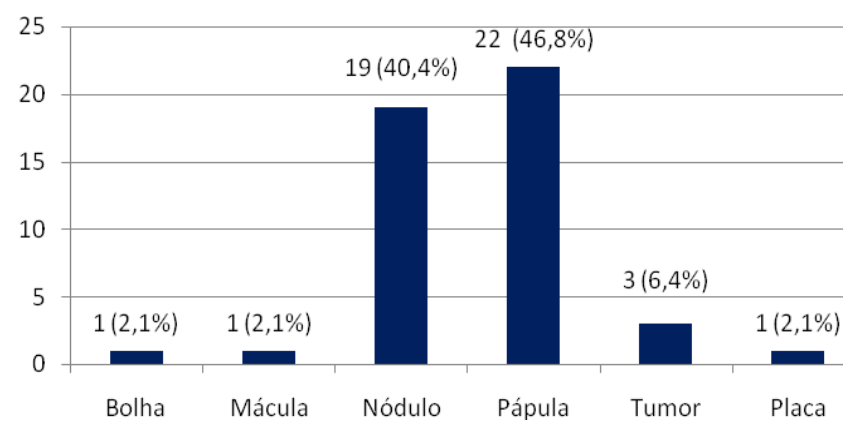

Gráfico 1: Prevalência da lesão fundamental associada às lesões orais descritas, em um centro de referência, Feira de Santana, 2005-2017

Fonte: Prontuários e fichas de biópsia dos pacientes atendidos no CRLB no período de 2005-2017.

* 12 dados ausentes ou não informados

As localizações prevalentes que foram a língua e lábio, ambos com $(25,9 \%)$, também corroboram com achados científicos consultados. Correa (2012) aponta que quanto à localização, o papiloma acometeu mais a língua, o lábio e o palato; o condiloma acuminado o 
lábio e a língua; a verruga vulgar acometeu mais a língua e o lábio enquanto que o carcinoma verrucoso ocorreu mais na área de mucosa.

Tabela 2: Distribuição das lesões orais verrucosas, de acordo com sua localização anatômica, em um centro de referência, Feira de Santana, 2005-2017

\begin{tabular}{lcc}
\hline & Frequência & $(\%)$ \\
\hline Gengiva & 4 & 7,4 \\
Lábio & 14 & 25,9 \\
Língua & 14 & 25,9 \\
Mandíbula & 1 & 1,9 \\
Mucosa jugal & 7 & 13,0 \\
Palato & 12 & 22,2 \\
Rebordo alveolar & 2 & 3,7 \\
\hline Total & $54^{*}$ & 100,0 \\
\hline
\end{tabular}

Fonte: Prontuários e fichas de biópsia dos pacientes atendidos no CRLB no período de 2005-2017.

* 5 dados ausentes ou não informados

Obsevou-se ainda que a média de idade dos pacientes acometidos era de 43 anos (D.P \pm 17 anos), sendo a maioria dos indivíduos negros $(59,5 \%)(\mathrm{n}=25)$ do gênero feminino $(78 \%)$ $(\mathrm{n}=46)$. Com relação à idade, o achado está em consonância com Serra (2015), segundo ele: "A análise dos registros em relação à faixa etária evidenciou que a verruga vulgar e o papiloma ocorrem com maior frequência entre 41 a 50 anos de idade”.

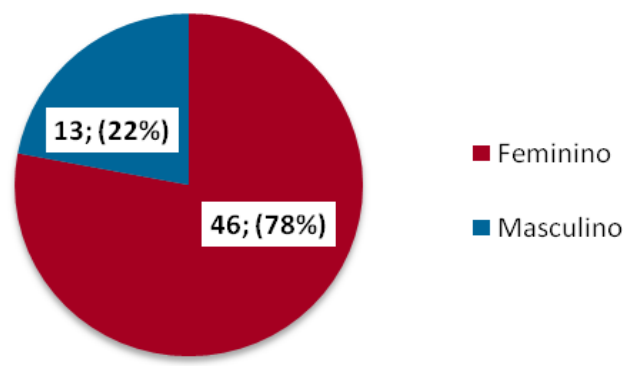

Gráfico 2: Gênero dos pacientes portadores das lesões orais verrucosas, em um centro de referência,

Feira de Santana, 2005-2017

Fonte: Prontuários e fichas de biópsia dos pacientes atendidos no CRLB no período de 2005-2017

No gráfico 2 observamos como população mais afetada os pacientes do gênero feminino numa proporção superior a 3:1. Apesar de nossos resultados demonstrarem uma clara predileção pelo sexo feminino, parece não haver um consenso na literatura quanto ao sexo mais acometido pelo papiloma de células escamosas. (FILHO et al, 2009).

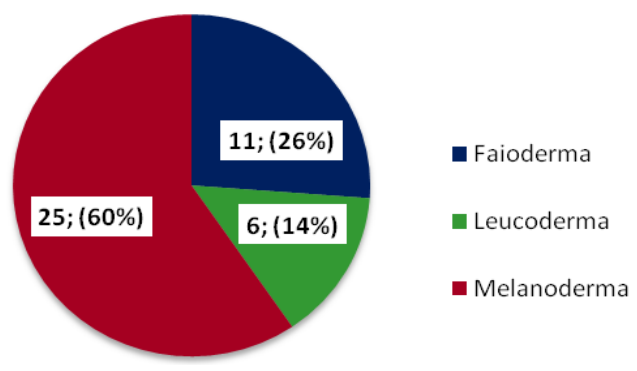

Gráfico 3:Cor dos pacientes portadores de lesões orais verrucosas, em um centro de referência, Feira de Santana, 2005-2017

Fonte: Prontuários e fichas de biópsia dos pacientes atendidos no CRLB no período de 2005-2017

* 17 dados ausentes ou não informados 
Quanto à cor da pele dos pacientes os dados não estão em conformidade com a literatura consultada. Essa discrepância pode ser justificada a partir composição populacional de Feira de Santana e microrregião que é predominantemente de indivíduos negros.

\section{CONSIDERAÇÕES FINAIS (ou Conclusão)}

Através desse trabalho foi possível se traçar um perfil clínico-epidemiológico da população do município de Feira de Santana e microrregião que tiveram diagnóstico histopatológico de lesão verrucosa na cavidade oral nos últimos 12 anos. Sendo a maioria dos pacientes: negros, casados e mulheres com em média 43 anos. Observa-se também que as lesões adotaram como sítio de predileção a língua e o lábio, além de apresentarem todas as características clínicas típicas de lesões associadas ao vírus HPV.

\section{REFERÊNCIAS}

BARRETO, R.C; DINIZ, M.F.F.M; GIUSEPPE, A.S.P; CELANI, H.R.B. 2014. Relação Papilomavírus (HPV) e Tumor Maligno da Cavidade Bucal. $R$ bras ci Saúde. 18(3):261-270. CARMO, E.D; FAVARETTO, H.D.R; BERTINI, F; AMADEI, S.U; BRANDÃO, A. A. H; ROSA, L. E. B. 2011 Estudo retrospectivo de tumores benignos bucais: análise de 42 anos. Rev. Bras. Cir. Cabeça Pescoço. 40(2):81-86.

CORREA, M.M.S.S. 2012. Lesões bucais associadas ao HPV: estudo epidemiológico. Universidade do Grande, Rio de Janeiro, Tese.

FILHO, P.R.S.M; PIVA, M. R; SANTOS, T.S; ANDRADE, E.S.S.A; SILVA, L.C.F. 2009. Papiloma de células escamosas da cavidade oral. Rev. Cir. Traumatol. Buco-Maxilo-fac. 9(3):69-73.

NEVILLE, B.W.; DAMM, D.D.; ALLEN, C.M.; BOUQUOT, J.E. 2016. Patologia Oral e Maxilofacial. 4. Ed. Rio de Janeiro: Elsevier.

SERRA, M.P. 2015. Estudo epidemiológico de lesões orais relacionadas ao HPV. UNIC. Cuiabá, Tese.

SILVA, B.S.F; YAMAMOTO, F.P; CURY, M.D.P; CURY, S.E.V. 2011. [online] Infecção por Papilomavírus Humano e Câncer Oral: Revisão da literatura atual. Cadernos UniFOA. Homepage: http//www.unifoa.edu.br/cadernos/edicao/17/115.pdf

SOBRAL, A.P.V; ALMEIDA, H.C.R; FONTES, J.P.S. 2014. Correlação do Papilomavírus Humano com o Carcinoma Epidermoide Bucal: Revisão Sistemática. Rev. cir. traumatol. buco-maxilo-fac.14(2):95-102. 